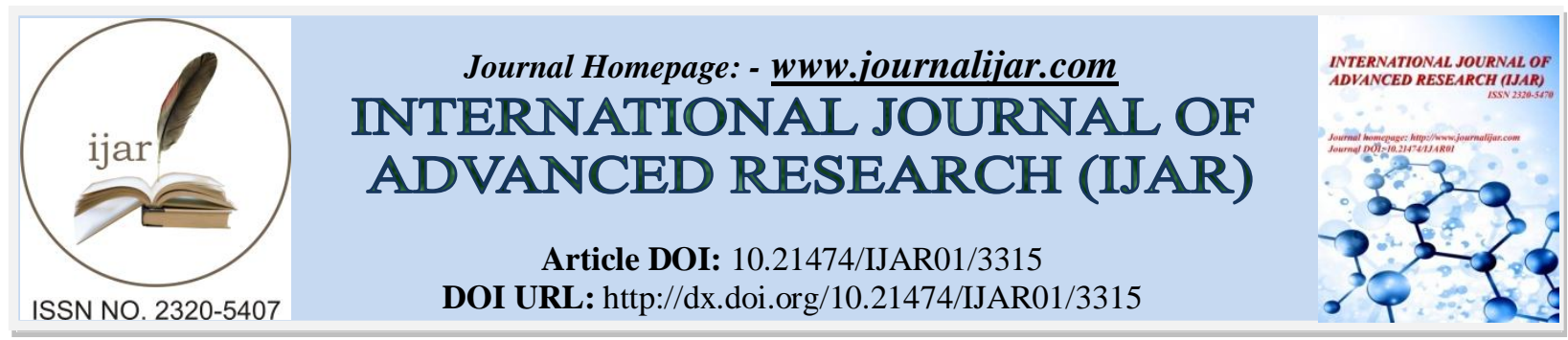

RESEARCH ARTICLE

\title{
CORRELATION OF PROLACTIN WITH THYROID-STIMULATING HORMONE AND FEMALE SEX HORMONES IN INFERTILE WOMEN.
}

Reham D. Alghonmeen, Omar M. Atrooz and Mohammad H. Abukhalil.

Department of Biological Sciences, Mutah University, Mutah, Jordan.

\section{Manuscript Info}

Manuscript History

Received: 26 December 2016

Final Accepted: 28 January 2017

Published: February 2017

Key words:-

Infertility, Prolactin, Thyroid stimulating hormone, Sex hormones.

\begin{abstract}
Hormonal and biochemical disturbances play an important role in development of infertility cases. Therefore, this study was conducted to evaluate the prolactin level and to explore the association between prolactin and thyroid stimulating hormone (TSH) and other hormones in the diagnosed infertile women in Ma'an governorate. The study was performed on 151 women (age group 20-40 years) who visited the Gynecology and Obstetrics Department at Ma'an governmental hospital. The study sample was divided into three groups: fertile group $(\mathrm{n}=27)$, primary infertile group $(\mathrm{n}=82)$ and secondary infertile group $(n=42)$. The results showed high incidence of prolactin abnormalities in both primary and secondary infertile women $(90 \%$ and $92 \%$, respectively). Furthermore, TSH abnormalities were found in $90 \%$ of primary infertile and \% 93 of secondary infertile women. In addition, the results revealed the positively significant correlation between TSH and the fertility. Positive correlations were found between the levels of prolactin and TSH in primary and secondary infertility. Also, there were positive correlations between the levels of prolactin and other hormones, including luteinizing hormone, follicle-stimulating hormone, testosterone, estradiol and progesterone. In conclusion, the present study revealed a significant correlation between prolactin and TSH and other hormones in infertile women. Therefore, assessment of serum TSH and prolactin levels are mandatory in the work up of all infertile women, especially those presenting with menstrual irregularities.
\end{abstract}

Copy Right, IJAR, 2017,. All rights reserved.

\section{Introduction:-}

Infertility is defined as the inability of non-contracepting couple to achieve pregnancy in one year (Roupa et al., 2009; Turchi, 2015). In the second decade of the new millennium, infertility remains a highly prevalent global condition. Infertility is estimated to affect between 8 and $12 \%$ of reproductive-aged couples worldwide (Inhorn and Patrizio, 2015). Primary infertility is diagnosed in couple who do not have any living children, while secondary infertility is diagnosed when female have been pregnant at least once but are unable to carry subsequent pregnancies (Whitehouse and Hollos, 2014). The female infertility can be a result of various conditions such as ovulation disorders, uterine or cervical abnormalities, fallopian tube damage or blockage, presence of endometriosis, primary ovarian insufficiency, pelvic adhesions and using of cytotoxic chemotherapy for cancer treatment (Abrao et al., 2013). 
Furthermore, disturbances of several hormones can play a crucial role in development of infertility cases. These hormonal disturbances may involve one or more than sex related hormones including prolactin (PRL), thyroid stimulating hormone (TSH), follicle-stimulating hormone (FSH), luteinizing hormone ( $\mathrm{LH})$, estrogen, progesterone and testosterone (Veeresh et al., 2015). Besides, prevalence of hypothyroidism in the reproductive age group is 2$4 \%$ and it has been shown to be the cause of infertility and habitual abortion (Verma et al., 2012; Kameswaramma, 2017). Hypothyroidism can be easily detected by assessing TSH levels in the blood. Many infertile women with hypothyroidism had associated hyperprolactinemia due to increased production of thyrotropin releasing hormone (TRH) in ovulatory dysfunction (Goswami et al., 2009).

Moreover, there is a number of scientific studies that have revealed significant correlations between some biochemical alterations and the infertility. These biochemical disturbances involve glucose concentration, lipid profile such as triglyceride, total cholesterol, high density lipoproteins (HDL) and low density lipoproteins (LDL) levels (Allahbadia and Merchant, 2011; Szaboova and Devendra, 2015). This study was, therefore, performed to evaluate the prolactin level in selected females (age group 20-40 years old ) from Ma'an governorate, and to explore the association between prolactin with TSH and other hormones, including sex hormones.

\section{Material and Method:- Study population:-}

The study was conducted on 151 women (age group 20-40 years) who visited the Gynecology and Obstetrics Department at Ma'an governmental hospital during 1/4/2014 to 30/9/2014 for a period of six months. The study was achieved in Ma'an governmental hospital laboratory. This study was conducted after taking informed, written consent of all patients. Infertile women on treatment for thyroid disorders or hyperprolactinemia were excluded from the study. All females underwent a complete physical examination, with measurement of weight, height and body Mass Index (BMI). Patient were grouped into three categories according to the Asia-Pacific classification of obesity: overweight (BMI $23-24.9 \mathrm{~kg} / \mathrm{m}^{2}$ ), class I obesity (BMI $25-29.9 \mathrm{~kg} / \mathrm{m}^{2}$ ) and class II obesity (BMI > 30 $\mathrm{kg} / \mathrm{m}^{2}$ ) (Flegal et al., 2012).

\section{Blood sample collection:-}

Blood samples from fasting participants were collected at 8.00-10.00 am. Venous blood was collected in an evacuated tube with a gel and a clot activator. Blood samples for FSH, LH, prolactin, TSH, testosterone and estradiol analysis were taken in second day of the menstrual cycle. For progesterone determination, the blood was taken at day 21 of the menstrual cycle. The serum samples were rapidly separated by centrifugation for 3-5 minutes at room temperature at $3500 \mathrm{rpm}$ and were separated into two tubes and stored at $-20 \mathrm{C}$ until analysis.

\section{Biochemical analysis:-}

The glucose levels in serum were measured by glucose hexokinase method (Hitach-912, Germany). The lipid profile, including triglyceride, cholesterol and HDL, were assessed by automated enzymatic colorimetric method (Hitach-912). Low LDL level was calculated by using the Friedewald formula $=($ Total cholesterol - HDL $)$ Triglyceride $/ 5$ (Friedewald et al., 1972). The normal reference ranges for glucose, triglyceride, cholesterol and $\mathrm{HDL}$ and LDL are $4.20-6.80 \mathrm{mmol} / \mathrm{L}, 0.70-1.90 \mathrm{mmol} / \mathrm{L}, 3.90-6.70 \mathrm{mmol} / \mathrm{L}, 1.06-1.52 \mathrm{mmol} / \mathrm{L}$ and $2.80-4.80$ $\mathrm{mmol} / \mathrm{L}$, respectively. TSH, LH, FSH, prolactin, testosterone, estradiol and progesterone were measured by electrochemiluminescence assay as per the instruction manual for Elecsys, 2010 (Roche Healthcare, Basel, Switzerland). The normal reference ranges for TSH, LH, FSH, prolactin, testosterone, estradiol and progesterone are $0.27-4.20 \mathrm{mIU} / \mathrm{ml}, 0.40-20 \mathrm{mIU} / \mathrm{ml}, 2.00-13.00 \mathrm{mIU} / \mathrm{ml}, 3.40-24.10 \mathrm{ng} / \mathrm{ml}, 0.025-15.00 \mathrm{ng} / \mathrm{ml}, 12.50-166.00 \mathrm{pg} / \mathrm{ml}$, 4.90-71.90 nmol/1, respectively.

\section{Statistical Analysis:-}

The data were presented as the mean \pm standard deviation (S.D). Association between variables was assessed by pearson's bivariate coefficient of correlation. $t$-test for independent samples was also used to determine significant difference between means of two continuous variables. Simple linear regression was also employed to analyze the data. $P \leq 0.05$ was considered significant. All statistical analyses were performed using the SPSS Statistics program, version 16.0 (IBM Corp., Armonk, NY, USA). 


\section{Results and Discussion:- \\ Patients' characteristics:-}

The mean age of the women included in the present study was $31.14 \pm 4.29$ years. Figure 1 illustrates the characteristics of the subjects according to infertility status. It was found that $20.53 \%$ of subjects were fertile women, while $47.0 \%$ of the subjects having primary infertility and $32.5 \%$ with secondary infertility. Some characteristics of the subjects, including irritable breast, overweight, amenorrhea, secretion of prolactin from the breast, facial growth increase and obesity, are shown in table 1. Most women in this study were obese according to BMI values. The relationship between obesity and reproductive functions has been known for many years (Dağ and Dilbaz, 2015) and it is still being explored (Klenov and Jungheim, 2014). Several mechanisms are involved in the relationship of fertility and obesity. The insulin resistance and leptin levels are increased and hyperandrogenemia occurs in obese women. Similarly, anovulation, changes in adipokine levels and the hypothalamic-pituitary-gonadal axis (HPG axis), and steroidogenesis in obese women affects the reproductive system (Pasquali et al., 2003; Chen $e t$ al., 2013).

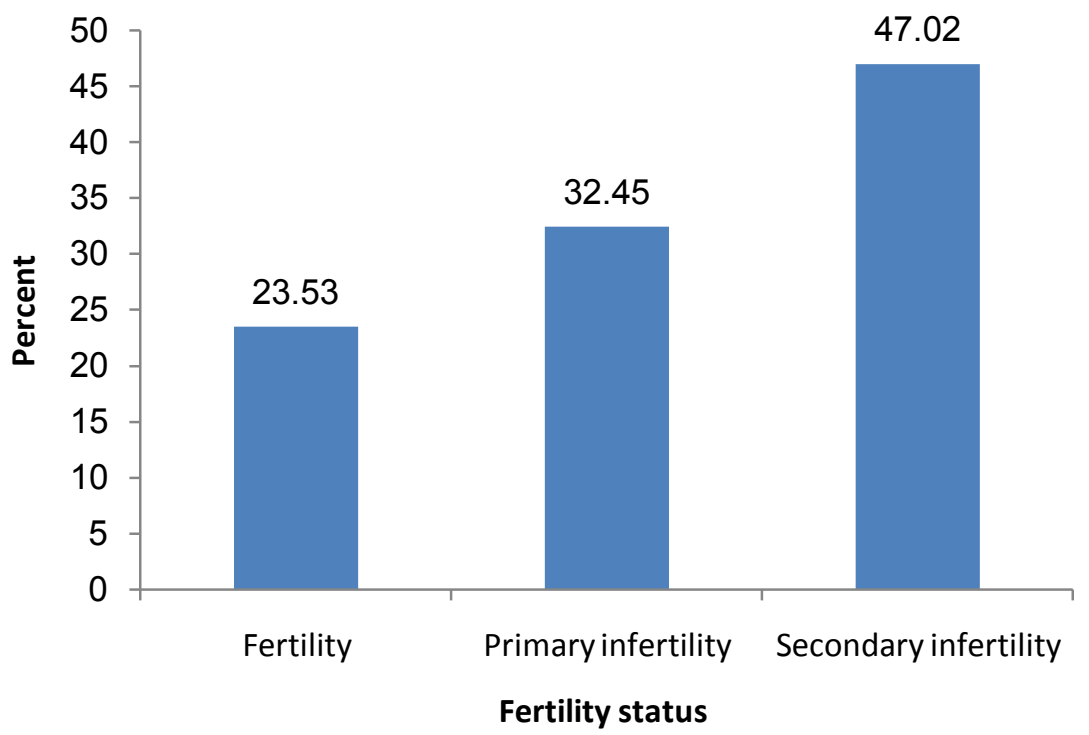

Figure 1:- Fertility status (\%).

Table 1:- Distribution of the study population characteristics $(\mathrm{n}=151)$

\begin{tabular}{|c|c|c|}
\hline Characteristics & Status & Number, percentage (\%) \\
\hline Fertility status & Fertility & $27(17.88)$ \\
& Secondary infertility Primary & $42(27.81)$ \\
& Infertility & $82(54.3)$ \\
\hline Hair loss & & $84(55.6)$ \\
\hline Weight increase & $93(61.6)$ \\
\hline Irritable Breast & $46(30.5)$ \\
\hline Amenorrhea & & $90(59.6)$ \\
\hline Secretion of prolactin from breast & & $73(48.3)$ \\
\hline Hair growth increase & $86(37.1)$ \\
\hline Body mass index: & $3(2.0)$ \\
$20-25$ & & $51(33.8)$ \\
$25-30$ & & $97(64.2)$ \\
\hline 30 & & \\
\hline 30 & & \\
\hline
\end{tabular}




\section{Serum levels of glucose and lipid profile:-}

The results were shown according to fertility status and were grouped into fertile, primary infertile and secondary infertile. Table 2 shows the levels of glucose and lipid profile in all groups. Glucose levels were significantly $(P \leq$ 0.01 ) higher in both secondary and primary groups than in fertile group. The high blood sugar is linked to polycystic ovarian syndrome, which in turn affects the balance of hormones in the body which affects the ovulation process thus negatively happen difficult pregnancy (Chamberlin et al., 2013). The most important hormones is insulin to keep blood sugar at a normal level. Estrogen works to make the body more receptive to insulin (which helps the action of insulin) and therefore it tends to reduce blood sugar, while progesterone works on blocking the action of insulin, and therefore it tends to increase the proportion of sugar in the blood, and there are wondrous harmony between hormones to work (Moce et al., 2005).

Some infertile women have a condition underlying their blood sugar problems. This condition is called polycystic ovarian syndrome (PCOS). In PCOS, too much testosterone is produced and this affects the ability of the eggs to mature within the ovaries (Wu et al., 2012). In turn, this will affect the balance of hormones in the body which affects the ovulation process thus negatively happen difficult pregnancy (Chamberlin et al., 2013).

Lipid profile, including cholesterol and LDL levels, were significantly $(P \leq 0.01)$ and $(P \leq 0.05)$, respectively, higher in both secondary and primary groups than in fertile group, while triglyceride and HDL showed insignificant changes compared to fertile group. High saturated fat raises LDL cholesterol in the body, which affects the body's sexual and reproductive ability. Cholesterol levels may be an important factor in healthy couples who do not have infertility problems. Cholesterol may be related in fertility because it is a building block of all hormones, male and female, such as estrogen and progesterone in women and testosterone in men, because they affect the sperm and semen of men quality, as well as the ovulation, in planting and maintaining a healthy pregnancy in women (Elis $e t$ al., 2013).

Table 2:- Levels of glucose and lipid profile (cholesterol, triglycerides, HDL and LDL) in the serum of all groups.

\begin{tabular}{|c|c|c|c|c|c|}
\hline Measurements & $\begin{array}{c}\text { Fertility } \\
(\mathrm{n}=27)\end{array}$ & $\begin{array}{c}\text { Secondary } \\
\text { infertility } \\
(\mathrm{n}=42)\end{array}$ & $P$ value * & $\begin{array}{c}\text { Primary } \\
\text { infertility } \\
(\mathrm{n}=82)\end{array}$ & $P$ value * \\
\hline Glucose $(\mathrm{mmol} / \mathrm{l})$ & $5.48 \pm 0.75$ & $6.07 \pm 0.97$ & $\leq 0.01$ & $6.02 \pm 0.94$ & $\leq 0.01$ \\
\hline LDL $(\mathrm{mmol} / \mathrm{l})$ & $3.49 \pm 0.46$ & $3.69 \pm 0.8$ & $\leq 0.01$ & $3.68 \pm 0.45$ & $\leq 0.01$ \\
\hline HDL $(\mathrm{mmol} / \mathrm{l})$ & $1.31 \pm 0.11$ & $1.34 \pm 0.09$ & $\mathrm{NS}$ & $1.36 \pm 0.09$ & $\mathrm{NS}$ \\
\hline Triglyceride $(\mathrm{mmol} / \mathrm{l})$ & $1.67 \pm 0.46$ & $2.16 \pm 0.6$ & $\mathrm{NS}$ & $2.12 \pm 0.52$ & $\mathrm{NS}$ \\
\hline Cholesterol $(\mathrm{mmol} / \mathrm{l})$ & $4.99 \pm 0.85$ & $5.82 \pm 0.85$ & $\leq 0.01$ & $5.64 \pm 0.67$ & $\leq 0.01$ \\
\hline
\end{tabular}

Results are expressed as the mean \pm S.D. NS: not significant

* Compared to the fertile group.

\section{Levels of hormones in serum:-}

The hormonal levels in serum are illustrated in table 3 . The prolactin levels were significantly $(P \leq 0.001)$ higher in both primary and secondary groups than in fertile group. Prolactin does not only work on body to increase the production of milk, but it also affects the ovulatory menstrual cycle. The high prolactin level in the blood is a common reason for the absence of ovulation cycle leading to infertility. This is why it is rare occurrence of pregnancy for women during the period of breast-feeding. Prolactin works on inhibition of two hormones needed for ovulation: FSH and gonadotropin releasing hormone $(\mathrm{GnRH})$. In addition to the lack of ovulation, it also can cause irregular menstruation periods (Cousineau and Domar, 2007; Shafik, 2009; Rebar, 2014).

The pituitary hormones that are related to the process of ovulation and cycle, including FSH and LH, were analyzed in the three studied groups. FSH hormone was significantly $(P \leq 0.01)$ higher in both primary and secondary fertility groups than in the fertile group. Likewise, the levels of LH were significantly $(P \leq 0.01)$ higher in both primary and secondary groups as compared to the normal fertile group.

LH measurement is useful in the diagnosis of ovarian bagging and recurrent miscarriage. The normal level of LH indicates that the ovary is active, but high number indicates failure of the ovary or the menopause stage of the woman. On the other hand, the low level of LH indicates a lack of secretions by the pituitary gland in general (Pakarainen et al., 2005; Berinder et al., 2007). The FSH measurement gives an idea of the remaining stocks of eggs in a woman's body. In addition, FSH helps to distinguish between the primary and secondary ovarian failures. 
The high levels of this hormone are consistent with the primary ovarian failure which is due to failure of ovarian development and chromosomal abnormalities such as Turner syndrome. Meaning while, the of secondary ovarian failure is caused by radiation and chemotherapy syndrome, PCOS and diseases of the thyroid and adrenal glands (Arachchige et al., 2012).

Table 3:- Hormones levels in the serum of all groups.

\begin{tabular}{|c|c|c|c|c|c|}
\hline Hormone level & $\begin{array}{c}\text { Fertility } \\
(\mathrm{n}=27)\end{array}$ & $\begin{array}{c}\text { Secondary } \\
\text { infertility } \\
(\mathrm{n}=42)\end{array}$ & $\begin{array}{c}P \text { value } \\
*\end{array}$ & $\begin{array}{c}\text { Primary } \\
\text { infertility } \\
(\mathrm{n}=82)\end{array}$ & $P$ value * \\
\hline Prolactin $(\mathrm{ng} / \mathrm{ml})$ & $16.26 \pm 6.68$ & $40.48 \pm 12.6$ & $\leq 0.001$ & $35.9 \pm 6.53$ & $\leq 0.001$ \\
\hline $\mathrm{LH}(\mathrm{mIU} / \mathrm{ml})$ & $11.19 \pm 4.48$ & $27.91 \pm 9.57$ & $\leq 0.01$ & $21.76 \pm 5.9$ & $\leq 0.01$ \\
\hline $\mathrm{FSH}(\mathrm{mIU} / \mathrm{ml})$ & $10.0 \pm 3.65$ & $25.08 \pm 8.54$ & $\leq 0.01$ & $19.4 \pm 5.58$ & $\leq 0.01$ \\
\hline $\mathrm{TSH}(\mathrm{mIU} / \mathrm{ml})$ & $3.24 \pm 1.11$ & $8.86 \pm 4.1$ & $\leq 0.01$ & $6.19 \pm 2.83$ & $\leq 0.01$ \\
\hline Progesterone $(\mathrm{nmol} / \mathrm{L})$ & $39.8 \pm 8.81$ & $14.97 \pm 9.72$ & $\leq 0.01$ & $19.14 \pm 6.69$ & $\leq 0.01$ \\
\hline Testosterone $(\mathrm{ng} / \mathrm{ml})$ & $5.71 \pm 3.75$ & $15.85 \pm 4.46$ & $\leq 0.01$ & $14.77 \pm 2.58$ & $\leq 0.01$ \\
\hline Estradiol $(\mathrm{pg} / \mathrm{ml})$ & $48.2 \pm 12.31$ & $19.14 \pm 16.4$ & $\leq 0.01$ & $20.11 \pm 6.73$ & $\leq 0.01$ \\
\hline
\end{tabular}

Results are expressed as the mean \pm S.D.

* Compared to the fertile group.

Furthermore, TSH levels were significantly $(P \leq 0.01)$ higher in both primary and secondary groups than in the fertile group. Thyroid hormones interact with reproductive hormones, estrogen and progesterone, to maintain the function of normal development of the egg and ovaries. The over secretion or hyposecretion of thyroid hormones could lead to the imbalance in these reproductive hormones, causing ovulation disorders, irregular menstrual cycle and reduced fertility (Crain et al., 2008; Artini et al., 2013).

Progesterone levels were significant $(P \leq 0.01)$ reduction in both primary and secondary groups as compared to the fertile group. Progesterone is considered of the most important hormones in a woman's body where it plays a major role in maintaining the regularity of menstrual cycle and thus is responsible for the pregnancy process. The shortage of this hormone in women is linked to some symptoms including delayed pregnancy, an increase in weight, especially over the abdominal area, disrupted menstrual cycle dates, low motivation and sexual coldness, fluctuation in mood and depression (Segar et al., 2013).

Testosterone levels were significantly $(P \leq 0.01)$ higher in both primary and secondary groups than in fertile group. High proportion of the male sex hormone (Testosterone) causes disorder and irregular menstrual cycle and ovulation where the menstruation comes every two or three months and sometimes only with the help of reproductive medicine. It is often accompanied by blisters or grain in the face and increased hair growth on the face, abdomen and chest (Barry et al., 2011).

Estradiol levels were significant $(P \leq 0.01)$ reduction in both primary and secondary groups when compared to the fertile group. Estrogen controls the thickness of uterine and the maturity of the egg when menstruation or pregnancy, reduces the $\mathrm{pH}$ in the vagina, and reduction of bacterial infection. Low estrogen levels may cause osteoporosis and menopause. Estrogen affects libido in women and controls the production of milk from the breasts (Stefanidou et al., 2009; Yu et al., 2014).

\section{Correlations between prolactin and different hormones:-}

Table 4 displays Pearson correlation coefficients between prolactin and TSH and sex hormones in primary and secondary infertility groups. The results in table 4 showed significant correlation between prolactin and TSH in both primary and secondary groups. In a previous study, Kumkum et al. (2006) showed a positive correlation of 1:4 was found between hypothyroidism and hyperprolactinemia. These findings are in accordance with the results of a study showed that there was a higher prevalence of hyperprolactinemia which positively correlated with thyroid disorder in infertile women (Goswami et al., 2009). In a recent study, Bassey et al. (2015) concluded that hyperprolactinemia with thyroid dysfunction may be a major contributor hormonal factor in infertility among infertile women. In addition, both groups showed significant correlation between prolactin and other hormones, including LH, FSH, prolactin, testosterone, estradiol and progesterone (Table 4). These findings are in line with the results of a study 
showed a positive correlation between estradiol and progesterone with hyperprolactinemia in infertile women (Isong et al., 2016).

Table 4:- Pearson correlation coefficients between prolactin and different hormones in primary and secondary infertility groups.

\begin{tabular}{|c|c|c|c|c|}
\hline & \multicolumn{2}{|c|}{ Secondary infertility } & \multicolumn{2}{c|}{ Primary infertility } \\
\hline Measurements & $r$ & $P$ value & $r$ & $P$ value \\
\hline LH(mIu/ml) & 0.783 & $0.003^{*}$ & 0.745 & $0.003^{*}$ \\
\hline FSH $(\mathrm{mIu} / \mathrm{ml})$ & 0.740 & $0.002^{*}$ & 0.684 & $0.002^{*}$ \\
\hline $\mathrm{TSH}(\mathrm{mIU} / \mathrm{ml})$ & 0.815 & $0.010^{*}$ & 0.677 & $0.010^{*}$ \\
\hline Progesterone $(\mathrm{nmol} / \mathrm{l})$ & -0.799 & $0.002^{*}$ & -0.725 & $0.002^{*}$ \\
\hline Testosterone $(\mathrm{ng} / \mathrm{ml})$ & 0.801 & $0.003^{*}$ & 0.681 & $0.003^{*}$ \\
\hline Estradiol $(\mathrm{Pg} / \mathrm{ml})$ & -0.803 & $0.004^{*}$ & -0.703 & $0.004^{*}$ \\
\hline
\end{tabular}

* Indicates significant at $\mathrm{P} \leq 0.05$

\section{Conclusion:-}

Hyperprolactinemia are mandatory in all infertile women especially those with amenorrhea. There was a significant high prevalence of hypothyroidism and hyperprolactinemia in the infertile women. A decrease in FSH level which could lead to the problems with the development of the follicle and infertility. There was a significant correlation between prolactin and TSH in both primary and secondary groups. Therefore, assessment of serum TSH and prolactin levels are mandatory in the work up of all infertile women, especially those presenting with menstrual irregularities.

\section{Acknowledgments:-}

The authors acknowledge Ma'an governmental hospital, Jordan, for providing necessary facilities to carry out the study. The authors also would like to thank the patients for their permission to be used in this study.

\section{References:-}

1. Abrao, M.S., Muzii, L., Marana, R., (2013): Anatomical causes of female infertility and their management. International Journal of Gynecology \& Obstetrics 123.

2. Allahbadia, G.N., Merchant, R., (2011): Polycystic ovary syndrome and impact on health. Middle East Fertility Society Journal 16, 19-37.

3. Arachchige, K., Mudhitha, K., Wardrop, R., Lim, E.M., Stuckey, B., Hadlow, N., (2012): Waiting for an elevated FSH-Too late a marker of reduced ovarian reserve? Australian and New Zealand Journal of Obstetrics and Gynaecology 52, 460-464.

4. Artini, P.G., Uccelli, A., Papini, F., Simi, G., Di Berardino, O.M., Ruggiero, M., Cela, V., (2013): Infertility and pregnancy loss in euthyroid women with thyroid autoimmunity. Gynecological Endocrinology 29, 36-41.

5. Barry, J.A., Hardiman, P.J., Saxby, B.K., Kuczmierczyk, A., (2011): Testosterone and mood dysfunction in women with polycystic ovarian syndrome compared to subfertile controls. Journal of Psychosomatic Obstetrics \& Gynecology 32, 104-111.

6. Bassey, I.E., Udoh, A.E., Essien, O.E., Isong, I.K.P., Gali, R.M., Archibong, E.E., (2015): Thyroid hormones and prolactin levels in infertile women in southern Nigeria. Journal of clinical and diagnostic research: JCDR 9, OC13.

7. Berinder, K., Hulting, A.L., Granath, F., Hirschberg, A.L., Akre, O., (2007): Parity, pregnancy and neonatal outcomes in women treated for hyperprolactinaemia compared with a control group. Clinical endocrinology 67, 393397.

8. Chamberlin, W., Middleton, J., Spain, J., Johnson, G., Ellersieck, M., Pithua, P., (2013): Subclinical hypocalcemia, plasma biochemical parameters, lipid metabolism, postpartum disease, and fertility in postparturient dairy cows. Journal of dairy science 96, 7001-7013.

9. Chen, X., Jia, X., Qiao, J., Guan, Y., Kang, J., (2013): Adipokines in reproductive function: a link between obesity and polycystic ovary syndrome. Journal of molecular endocrinology 50, R21-R37.

10. Cousineau, T.M., Domar, A.D., (2007): Psychological impact of infertility. Best Practice \& Research Clinical Obstetrics \& Gynaecology 21, 293-308.

11. Crain, D.A., Janssen, S.J., Edwards, T.M., Heindel, J., Ho, S.-m., Hunt, P., Iguchi, T., Juul, A., McLachlan, J.A., Schwartz, J., (2008): Female reproductive disorders: the roles of endocrine-disrupting compounds and developmental timing. Fertility and sterility 90, 911-940. 
12. Dağ, Z.Ö., Dilbaz, B., (2015): Impact of obesity on infertility in women. Journal of the Turkish German Gynecological Association 16, 111.

13. Elis, S., Coyral-Castel, S., Freret, S., Cognié, J., Desmarchais, A., Fatet, A., Rame, C., Briant, E., Maillard, V., Dupont, J., (2013): Expression of adipokine and lipid metabolism genes in adipose tissue of dairy cows differing in a female fertility quantitative trait locus. Journal of dairy science 96, 7591-7602.

14. Flegal, K.M., Carroll, M.D., Kit, B.K., Ogden, C.L., (2012): Prevalence of obesity and trends in the distribution of body mass index among US adults, 1999-2010. Jama 307, 491-497.

15. Friedewald, W.T., Levy, R.I., Fredrickson, D.S., (1972): Estimation of the concentration of low-density lipoprotein cholesterol in plasma, without use of the preparative ultracentrifuge. Clinical chemistry 18, 499-502.

16. Goswami, B., Patel, S., Chatterjee, M., Koner, B., Saxena, A., (2009): Correlation of prolactin and thyroid hormone concentration with menstrual patterns in infertile women. Journal of Reproduction \& Infertility 10, 207-212.

17. Inhorn, M.C., Patrizio, P., (2015): Infertility around the globe: new thinking on gender, reproductive technologies and global movements in the 21st century. Human reproduction update, dmv016.

18. Isong, I., Okhormhe, Z., Eze-Bassey, I., Okpokam, D., Usoro, C., (2016): Levels of prolactin, progesterone, estradiol, luteinizing hormone and follicle stimulating hormone in infertile women in Calabar, Nigeria. International Journal of Reproduction, Contraception, Obstetrics and Gynecology 5, 803-807.

19. Kameswaramma, K., (2017): Study of correlation of thyroid profile and clinical parameters in patients with infertility. International Journal of Reproduction, Contraception, Obstetrics and Gynecology 5, 1410-1413.

20. Klenov, V.E., Jungheim, E.S., (2014): Obesity and reproductive function: a review of the evidence. Current Opinion in Obstetrics and Gynecology 26, 455-460.

21. Kumkum, A., Jasmine, K., Shweta, G., PAL, A.N., (2006): Hyperprolactinema and its coorelation with hypothyroidism in infertile women.

22. Pakarainen, T., Zhang, F.-P., Mäkelä, S., Poutanen, M., Huhtaniemi, I., (2005): Testosterone replacement therapy induces spermatogenesis and partially restores fertility in luteinizing hormone receptor knockout mice. Endocrinology 146, 596-606.

23. Pasquali, R., Pelusi, C., Genghini, S., Cacciari, M., Gambineri, A., (2003): Obesity and reproductive disorders in women. Human reproduction update 9, 359-372.

24. Rebar, R., 2014. Evaluation of amenorrhea, anovulation, and abnormal bleeding.

25. Roupa, Z., Polikandrioti, M., Sotiropoulou, P., Faros, E., Koulouri, A., Wozniak, G., Gourni, M., (2009): Causes of infertility in women at reproductive age. HSJ 3, 80-87.

26. Segar, J.L., Volk, K.A., Lipman, M.H., Scholz, T.D., (2013): Thyroid hormone is required for growth adaptation to pressure load in the ovine fetal heart. Experimental physiology 98, 722-733.

27. Shafik, H., (2009): Immunoradiometric assay for in-vitro determination of prolactin hormone in human serum or plasma using solid phase anti-PRL cellulose particles. Journal of radioanalytical and nuclear chemistry $281,639$.

28. Stefanidou, M., Maravelias, C., Spiliopoulou, C., (2009): Human exposure to endocrine disruptors and breast milk. Endocrine, Metabolic \& Immune Disorders-Drug Targets (Formerly Current Drug Targets-Immune, Endocrine \& Metabolic Disorders) 9, 269-276.

29. Szaboova, R., Devendra, S., (2015): Infertility in a young woman with Type 2 diabetes. London journal of primary care 7, 55-57.

30. Turchi, P., (2015): Prevalence, definition, and classification of infertility, Clinical Management of Male Infertility, Springer, pp. 5-11.

31. Veeresh, T., Moulali, D., Sarma, D., (2015): A Study on Serum FSH, LH and Prolactin Levels in Women with Thyroid Disorders. International Journal of Scientific and Research Publications 5, 250-254.

32. Verma, I., Sood, R., Juneja, S., Kaur, S., (2012): Prevalence of hypothyroidism in infertile women and evaluation of response of treatment for hypothyroidism on infertility. International Journal of Applied and Basic Medical Research $2,17$.

33. Whitehouse, B., Hollos, M., (2014): Definitions and the Experience of Fertility Problems: Infertile and Sub- fertile Women, Childless Mothers, and Honorary Mothers in Two Southern Nigerian Communities. Medical anthropology quarterly 28, 122-139.

34. Wu, S., Divall, S., Wondisford, F., Wolfe, A., (2012): Reproductive tissues maintain insulin sensitivity in dietinduced obesity. Diabetes 61, 114-123.

35. Yu, W., Zheng, H., Lin, W., Tajima, A., Zhang, Y., Zhang, X., Zhang, H., Wu, J., Han, D., Rahman, N.A., (2014): Estrogen promotes Leydig cell engulfment by macrophages in male infertility. The Journal of clinical investigation $124,2709-2721$. 